Journal of Accident and Emergency Medicine 1995 12, 212-213

CASE REPORT

\title{
Occupational phosgene poisoning: a case report and review
}

\author{
J. P. WYATT \& C. A. ALLISTER
}

Department of Accident and Emergency, Royal Alexandra Hospital, Paisley, Strathclyde, UK

\section{SUMMARY}

Phosgene is a highly toxic gas to which some workers may be occupationally exposed. This case report demonstrates the possibility of refrigeration workers suffering phosgene poisoning after heating certain chlorinated fluorocarbons ('freons'). The need to suspect phosgene exposure and observe such patients is emphasized, especially in view of the delay in clinical deterioration observed in some patients who subsequently develop adult respiratory distress syndrome.

Keywords: occupational health, phosgene

\section{INTRODUCTION}

Phosgene (carbonyl chloride; chemical formula $\mathrm{COCl}_{2}$ ) has been widely used as a chemical weapon in the past, particularly in World War I. ${ }^{1,2}$ Although use in this capacity appears to be currently less widespread, phosgene continues to be used in various industrial processes. ${ }^{3}$ Occupational exposure after an accident in an industrial plant known to contain phosgene is unlikely to present problems of recognition, but phosgene exposure can also occur in other seemingly innocuous situations, as is illustrated by the following case report.

\section{CASE REPORT}

A 43-year-old man was involved in the demolition of a refrigeration plant. Whilst using a hot welding torch to cut through a refrigeration pipe which contained the freon chlorodifluoromethane, he was exposed to a peculiar 'musty smelling gas'. He initially experienced lacrimation, nausea, and a cough with burning sensation in his mouth and throat and he subsequently experienced dyspnoea and chest pain. On arrival at the accident and emergency (A\&E) department he was dyspnoeic (respiratory rate $24 \mathrm{~min}^{-1}$ ) and tachycardic (pulse $100 \mathrm{~min}^{-1}$ ) and noted to have pharyngeal erythema. The remainder of his examination and investigations (including ECG, chest radiograph and arterial blood gases) were normal. After consultation to determine the effect of heating chlorodifluoromethane, a diagnosis of phosgene gas exposure was made. The patient was admitted for observation for $24 \mathrm{~h}$. Following discharge he made a slow recovery, complaining of lethargy and exertional dyspnoea, which prevented him from returning to work for the next 2 weeks.

\section{DISCUSSION}

This patient's symptoms were typical of those seen after exposure to phosgene at a concentration exceeding 3 parts per million. ${ }^{4}$ Phosgene is produced when extreme heat is applied to chlorinated fluorocarbons. The possibility of occupational exposure of refrigeration workers to phosgene has been suggested previously, but has not been reported in the UK. ${ }^{5}$ Adequate purging of refrigeration pipes before welding would help to reduce this risk significantly.

Phosgene is a highly toxic gas, and exposure may have a fatal outcome. ${ }^{6}$ Respiratory symptoms may be delayed by a latent period of several hours before adult respiratory distress syndrome becomes apparent. ${ }^{4,6}$ Diagnosis of phosgene exposure may be straightforward in workers presenting from certain industrial plants where there is a recognized risk. Such workers should be encouraged to wear phosgene indicator badges, which act as dose-dependent colorimeters, allowing an estimation of the degree of exposure. ${ }^{7}$ In other situations, in the absence of any specific or reliable diagnostic test, a high index of suspicion is required. Suspicion should be aroused in particular by the characteristic history of a peculiar musty smelling gas. Doctors need to 
Occupational

Phosgene

Poisoning be aware of the risk of phosgene exposure when heat is applied to certain chlorinated fluorocarbons commonly used in a variety of industries (including refrigeration and metal 'degreasing' plants).

Any patient with a history and symptoms that suggest the possibility of phosgene exposure should be given oxygen and admitted for observation for at least $24 \mathrm{~h}$. Despite several studies, no parameters in the latent period allow either a definite diagnosis or an accurate assessment of the degree of exposure..$^{8}$ Instead, whilst waiting for the development of potential complications, reliance has to be placed on the combination of the history of severity of symptoms and the likely duration of exposure. ${ }^{8}$

The pathogenesis of phosgene poisoning is not clearly understood. The old theory that phosgene produces lung injury entirely by hydrolysis, liberating hydrochloric acid $\left(\mathrm{COCl}_{2}+\mathrm{H}_{2} \mathrm{O} \rightarrow \mathrm{CO}_{2}+\right.$ $2 \mathrm{HCl}$ ), has been abandoned. ${ }^{4}$ The miniscule amounts of phosgene involved in clinical poisoning release similarly tiny amounts of hydrochloric acid, which would cause little damage. Phosgene is $\mathbf{8 0 0}$ times more toxic than the hydrochloric acid it produces, so other mechanisms must be involved. Acylation reactions producing additional toxic chemicals may be important. ${ }^{4}$

Various first-aid measures for phosgene exposure have been recommended. In its Medical Manual of Defence against Chemical Agents the Ministry of Defence recommends the use of a steroid inhaler, warmth, rest, oxygen and codeine (to control coughing). ${ }^{9}$ There is no known antidote for phosgene, but severe cases benefit from close monitoring and positive pressure ventilation. ${ }^{10}$ The role of steroids remains controversial. ${ }^{10}$ Complete recovery after phosgene exposure may take a long time, and most patients continue to complain of exertional dyspnoea for several months after exposure. ${ }^{111}$ Follow-up after hospital discharge is therefore recommended.

\section{ACKNOWLEDGEMENT}

The authors thank Dr I.S. Symington, Consultant in Occupational Health, for his assistance.

\section{REFERENCES}

1. Sandall G. (1922) The late effects of gas poisoning. Lancet ii, 857-859.

2. Vedder E.B. (1923) Medical Aspects of Chemical Warfare. Williams and Wilkins, Baltimore.

3. Sidell F.R. (1990) What to do in an unthinkable chemical warfare attack or accident. Postgraduate Medicine 88, 70-84.

4. Diller W.F. (1985) Pathogenesis of phosgene poisoning Toxicology and Industrial Health 1(2), 7-15.

5. Rinzema L.C. and Silverstein L.G. (1972) Hazards from chlorinated hydrocarbon decomposition during welding. American Industrial Hygiene Association Journal 33, 35-40.

6. Regan R.A. (1985) Review of clinical experience in handling phosgene exposure cases. Toxicology and Industrial Health 1(2), 69-72.

7. Matherne R.N., Lubs P.L. \& Kerfoot E.J. (1981) The development of a passive dosimeter for immediate assessment of phosgene exposures. American Industrial Hygiene Association Journal 42, 631.

8. Diller W.F. (1985) Early diagnosis of phosgene overexposure. Toxicology and Industrial Health 1(2), 73-80.

9. Ministry of Defence, (1987) Medical Manual of Defence Against Chemical Agents, sixth edition. H.M.S.O., London.

10. Diller W.F. (1985) Therapeutic strategy in phosgene poisoning. Toxicology and Industrial Health 1(2), 9399.

11. Diller W.F. (1985) Late sequelae after phosgene poisoning. Toxicology and Industrial Health 1(2), 129-133. 